\title{
Evaluation of acute peri-myocarditis with cardiac magnetic resonance imaging
}

\author{
Scharen, E ; Paul, M ; Lüscher, T F ; Corti, R ; Manka, R
}

Posted at the Zurich Open Repository and Archive, University of Zurich

ZORA URL: https://doi.org/10.5167/uzh-56476

Journal Article

Published Version

Originally published at:

Scharen, E; Paul, M; Lüscher, T F; Corti, R; Manka, R (2011). Evaluation of acute peri-myocarditis with cardiac magnetic resonance imaging. Cardiovascular Medicine, 14(9):266-268. 


\section{Evaluation of acute peri-myocarditis with cardiac magnetic resonance imaging}

Eva Scharen ${ }^{a}$, Matthias Paul ${ }^{b}$,Thomas F. Lüscher ${ }^{a}$, Roberto Corti ${ }^{a}$, Robert Manka ${ }^{a}$

a CardioVascular Centre / Cardiology, University Hospital Zurich, Switzerland

${ }^{b}$ NIHR Biomedical Research Centre at Guy's and St Thomas' NHS Foundation Trust, London, United Kingdom

\section{Case report}

A 20-year-old man presented to the emergency department of a district general hospital early in the morning with substernal burning chest pain radiating to the scapulae. The symptoms started two days before during the night and subsided spontaneously. Dyspnea, and an increase of pain on inspiration or on change of position were denied. The patient reported having initiated antibiotic therapy himself as he had suffered from a cold with a sore throat and pyrexia of 39 degrees Celsius a week before the chest pain had started. At presentation, he was in a reduced general state of health. Vital signs were as follows: blood pressure
143/107 mm Hg, heart-rate 65/min, temperature 36.5 degrees Celsius and arterial oxygen saturation 100\% on ambient air. The physical examination was unremarkable, and no murmurs or pericardial friction rub were noted. The initial blood results showed a slight elevation of the inflammation values and a significant increase of the cardiac biomarkers (Troponin I $10.12 \mu \mathrm{g} / \mathrm{l}$ $[<0.1 \mu \mathrm{g} / \mathrm{l}]$, CK-MB $25 \mu \mathrm{g} / \mathrm{l}[<5 \mu \mathrm{g} / \mathrm{l}])$. The electrocardiogram demonstrated sinus rhythm and slight ST-elevations in the infero-lateral leads. To exclude an acute coronary syndrome, the patient was immediately referred to the university hospital for an urgent coronary angiogram. This demonstrated normal coronary arteries (fig. 1).
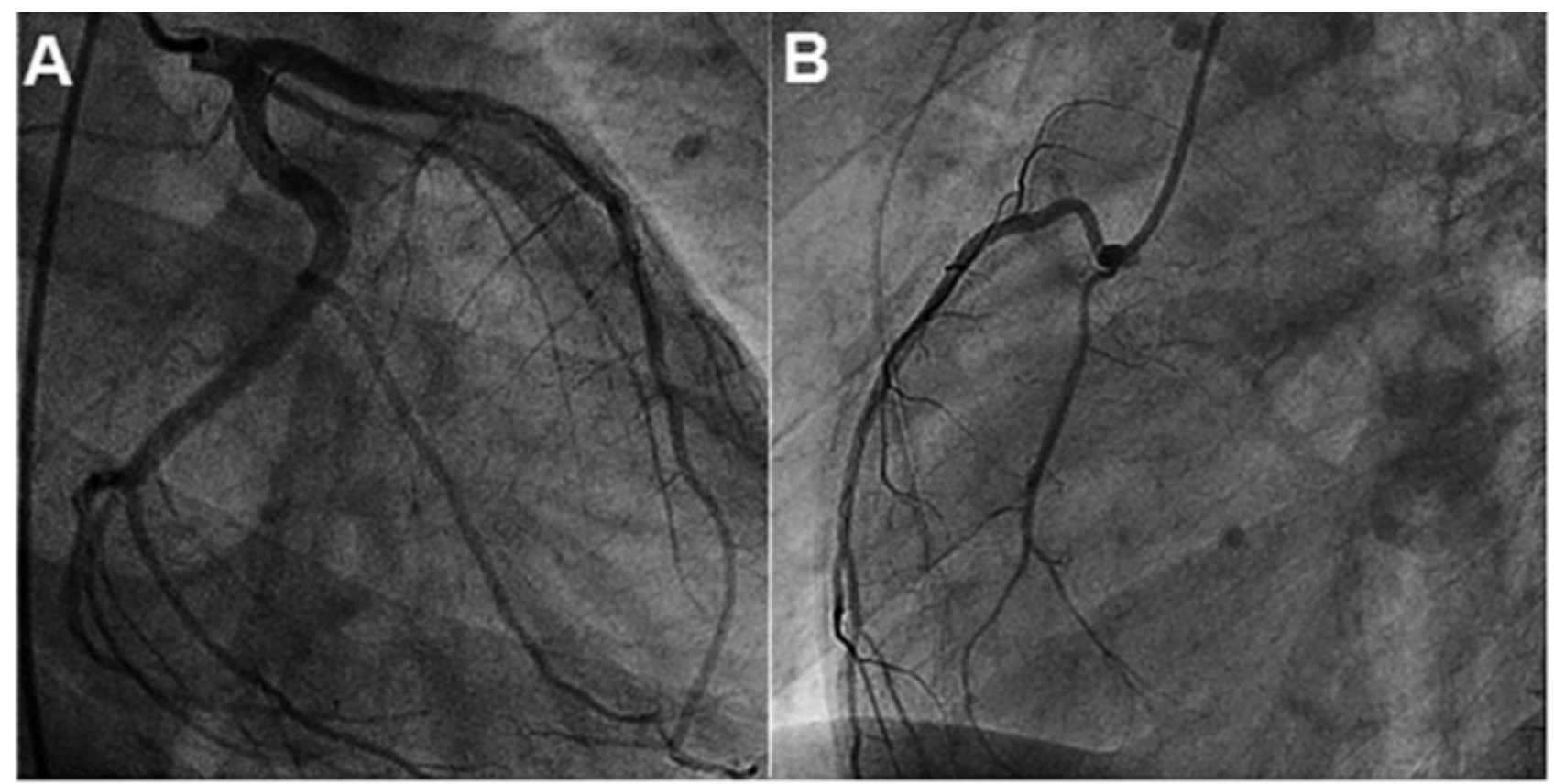

Figure 1

Coronary angiography: Patent left anterior descending artery, left circumflex artery (A) and right coronary artery (B).

Funding / potential competing interests:

No financial support and

no other potential conflict

of interest relevant to this

article were reported.
Correspondence:

Robert Manka, MD

CardioVascular Centre

University Hospital Zurich

$\mathrm{CH}-8091$ Zurich

Switzerland

robert.manka@usz.ch 
The history, clinical presentation and findings were consistent with acute peri-myocarditis, which was most likely post-viral. Cardiac magnetic resonance imaging performed the same day further supported the diagnosis. Global systolic left ventricular function was normal with hypokinesia in basal to midventricular infero-lateral segments with a small pericardial effusion in the area of the basal infero-lateral wall. On T2weighted and late gadolinium enhancement images, the signal intensity was increased in the basal lateral wall, predominantly in the epicardial layer, suggesting local oedema (fig. 2).

A relief of symptoms was achieved with NSAR and continued antibiotic therapy. We advised the patient to abstain from vigorous exercise for the next three months.

At follow-up three months later, the patient was free from any discomfort. His physical examination, blood results, resting ECG and echocardiography were completely normal.

\section{Discussion}

Peri-myocarditis is a focal or diffuse inflammation of variable degree of the pericardium and myocardium and is usually caused in developed countries by viral

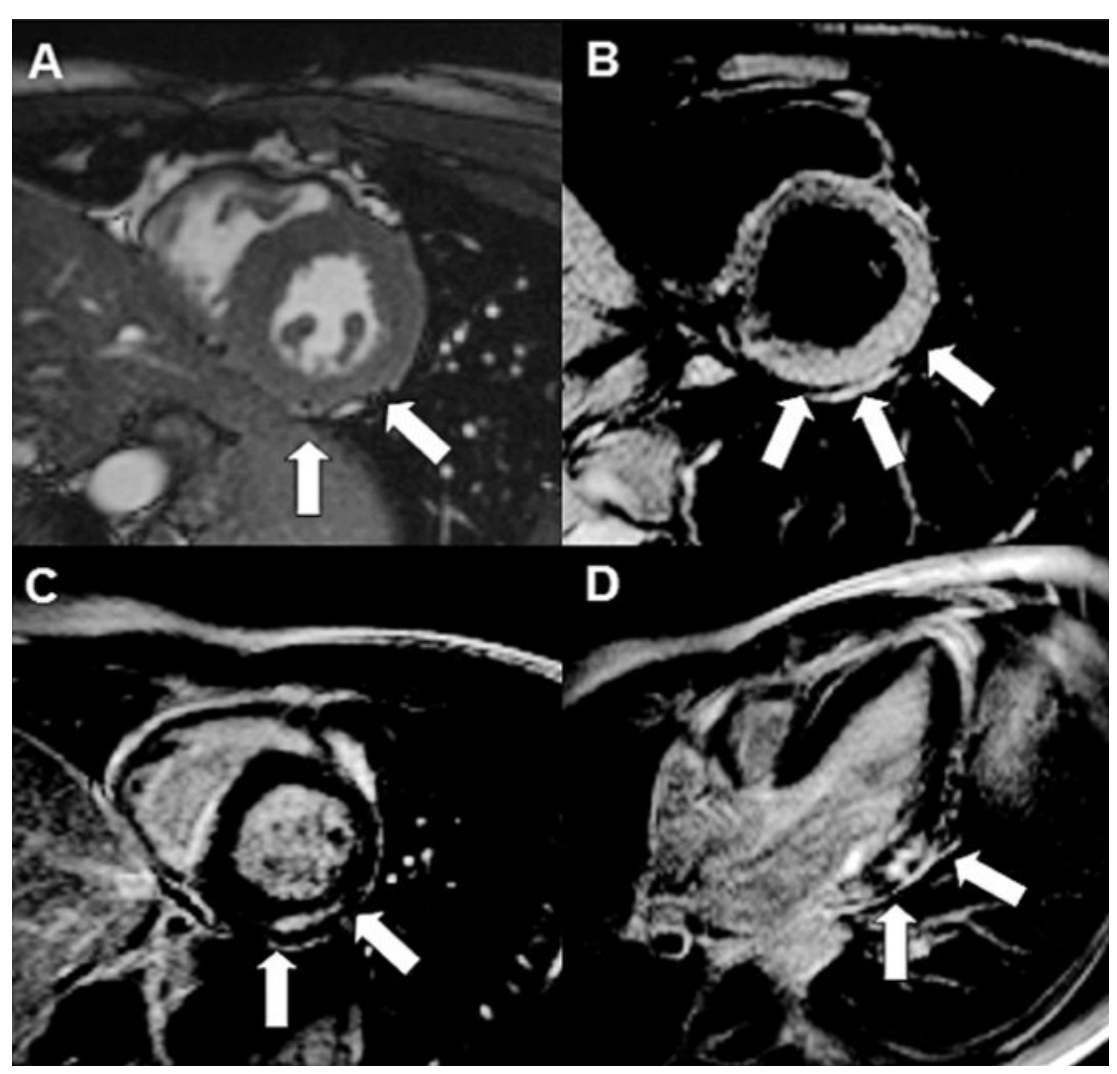

Figure 2

Short-axis cine image at end-systole demonstrates hypokinesia of the infero-lateral left ventricle (LV) wall (A; white arrows). T2-weighted image (B) shows oedema of the lateral LV wall (white arrows) with corresponding late enhancement infero-lateral in the short-axis (C) and three chamber view ( $D$; white arrows). infections. Younger individuals (median age 42 years) with a predisposing genetic background are typically affected [1, 2]. Our young patient also reported symptoms of a viral infection.

Damage is caused by direct viral cytolytic or cytotoxic effects with release of intracellular proteins, which mobilise inflammatory cells to the infected foci. This leads to tissue oedema and later to fibrosis. The classical symptom is position-dependant chest pain relieved by sitting forward and worsened by lying down. Infrequently, heart failure and arrhythmias occur which may even lead to sudden cardiac death. Exercise increases the risk of fatal arrhythmias and hence abstinence from sport or other vigorous exercise is recommended for 3 to 6 months [3, 4]. In many cases the clinical course is asymptomatic with the consequence that the syndrome is underreported. As in our patient, the clinical course usually results in a complete recovery without left ventricular impairment but in some cases a reduced function of variable degree persists.

Due to the high spatial resolution and the unique ability to visualise myocardial and pericardial oedema and fibrosis, cardiac magnetic resonance imaging is the ideal imaging modality to assess patients with suspected peri-myocarditis. Differentiation between coronary heart disease and peri-myocarditis is possible. Late gadolinium enhancement is the most powerful approach to assess myocarditis, however, other imaging techniques like T2weighted imaging for example in combination with late gadolinium enhancement may even improve the diagnostic performance [5]. In peri-myocarditis, findings include the presence of mainly epicardial and mid-wall late gadolinium enhancement, and an increased focal $\mathrm{T} 2$-signal representing myocardial oedema. If visual analysis is inconclusive, quantitative analysis may be helpful since an increased T2 signal ratio between the myocardium and the skeletal muscle may indicate myocarditis [6, 7]. Late gadolinium enhancement in myocarditis can be distinguished from ischemic genesis as it is typically localised in the epicardium extending into the mid-myocardium whereas in ischemic heart disease the endocardium is always affected with variable extension into the mid-myocardium and epicardium and corresponds to a coronary artery territory [8, 9]. Furthermore, in myocarditis the 
most common location for lesions is the lateral wall [10].

As in our patient, the indication for performing cardiac magnetic resonance imaging in acute peri-myocarditis is, in most cases, the affirmation of the suspected diagnosis after exclusion of coronary heart disease by coronary angiogram. Furthermore in patients with potential acute ST elevation myocardial infarction, a time loss by performing cardiac magnetic resonance imaging first is unacceptable [11]. In patients with low pre-test probability regarding coronary artery disease and typical symptoms of peri-myocarditis as in our case, it would be reasonable to omit the coronary angiogram and to provide the diagnosis and extent of myocardial involvement by cardiac magnetic resonance imaging [12].

In addition, cardiac magnetic resonance imaging can be used to guide myocardial biopsy [9, 10]. Endomyocardial biopsy is the gold standard to definitely diagnose myocarditis. However, it is invasive and complications may occur. Therefore, it is only recommended in patients with acute dilated cardiomyopathy associated with haemodynamic compromise and in those with life-threatening arrhythmias. This is to establish the diagnosis and prognosis and to guide therapy [13]. As a result of the focal manifestation of myocarditis, there is a high sample error and the sensitivity of endomyocardial biopsy is low [14]. Cardiac magnetic resonance imaging can be used to obtain samples from the affected regions which allows significant improvement in the sensitivity of myocardial biopsy [10, 15].

\section{References}

1 Cooper LT, Jr. Myocarditis. N Engl J Med. 2009;360(15):1526-38.

2 Imazio M, Trinchero R. Myopericarditis: Etiology, management, and prognosis. Int J Cardiol. 2008;23;127(1):17-26

3 Maron BJ, Ackerman MJ, Nishimura RA, Pyeritz RE, Towbin JA, Udelson JE. Task Force 4: HCM and other cardiomyopathies, mitral valve prolapse, myocarditis, and Marfan syndrome. J Am Coll Cardiol. 2005; 45(8):1340-5.
4 Pelliccia A, Corrado D, Bjørnstad HH, Panhuyzen-Goedkoop N, Urhausen A, Carre F, et al. Recommendations for participation in competitive sport and leisure-time physical activity in individuals with cardiomyopathies, myocarditis and pericarditis. Eur J Cardiovasc Prev Rehabil. 2006;13(6):876-85.

5 Abdel-Aty H, Boye P, Zagrosek A, Wassmuth R, Kumar A, Messroghli $\mathrm{D}$, et al. Diagnostic performance of cardiovascular magnetic Resonance in patients with suspected acute myocarditis: comparison of different approaches. J Am Coll Cardiol. 2005;45(11):1815-22.

6 Gutberlet M, Spors B, Thoma T, Bertram H, Denecke T, Felix R, et al. Suspected chronic myocarditis at cardiac MR: diagnostic accuracy and association with immunohistologically detected inflammation and viral persistence. Radiology. 2008;246(2):401-9.

7 Gagliardi MG, Bevilacqua M, Di Renzi P, Picardo S, Passariello R, Marcelletti C. Usefulness of magnetic resonance imaging for diagnosis of acute myocarditis in infants and children, and comparison with endomyocardial biopsy. Am J Cardiol. 1991;68(10):1089-91.

8 Friedrich MG, Strohm O, Schulz-Menger J, Marciniak H, Luft FC, Dietz $\mathrm{R}$. Contrast media enhanced magnetic resonance imaging visualizes myocardial changes in the course of viral myocarditis. Circulation. 1998;97(18):1802-9.

9 De Cobelli F, Pieroni M, Esposito A, et al. Delayed gadolinium-enhanced cardiac magnetic resonance in patients with chronic myocarditis presenting with heart failure or recurrent arrhythmias. J Am Coll Cardiol. 2006;47(8):1649-54.

10 Mahrholdt H, Goedecke C, Wagner A, et al. Cardiovascular magnetic resonance assessment of human myocarditis: A comparison to histology and molecular pathology. Circulation. 2004;109(10):1250-8.

11 Rathore SS, Curtis JP, Chen J, Wang Y, Nallamothu BK, Epstein AJ, et al. Association of door-to-balloon time and mortality in patients admitted to hospital with ST elevation myocardial infarction: national cohort study. BMJ. 2009;338:b1807. doi:10.1136/bmj.b1807.

12 Goitein O, Matetzky S, Beinart R, Di Segni E, Hod H, Bentancur A, et al. Acute myocarditis: noninvasive evaluation with cardiac MRI and transthoracic echocardiography. AJR Am J Roentgenol. 2009;192(1): 254-8.

13 Cooper LT, Baughman KL, Feldman AM, Frustaci A, Jessup M, Kuhl $\mathrm{U}$, et al. The role of endomyocardial biopsy in the management of cardiovascular disease: a scientific statement from the American Heart Association, the American College of Cardiology, and the European Society of Cardiology. Circulation. 2007;116(19):2216.

14 Narula J, Khaw BA, Dec GW, et al. Diagnostic accuracy of antimyosin scintigraphy in suspected myocarditis. J Nucl Cardiol. 1996;3(5): 371-81.

15 Mavrogeni S, Spargias C, Bratis C, Kolovou G, Markussis V, Papadopoulou $\mathrm{E}$, et al. Myocarditis as a precipitating factor for heart failure: evaluation and 1-year follow-up using cardiovascular magnetic resonance and endomyocardial biopsy. Eur J Heart Fail. May 31, 2011: hfr052v1-hfr052. 